\title{
DISTRIBUSI SPASIAL KARAKTERISTIKTANAH TAMBAK DI KABUPATEN PANGKEP PROVINSI SULAWESI SELATAN
}

\author{
Rachmansyah dan Akhmad Mustafa \\ Balai Riset Perikanan Budidaya Air Payau \\ Jl. Makmur Dg. Sitakka No. 129, Maros 90512, Sulawesi Selatan \\ E-mail: litkanta@indosat.net.id
}

(Naskah diterima: 3 Agustus 2011; Disetujui publikasi: 8 November 2011)

\begin{abstract}
ABSTRAK
Identifikasi distribusi spasial karakteristik tanah memiliki peran penting dalam sistem bio- lingkungan termasuk lingkungan tambak, sehingga dilakukan penelitian yang bertujuan untuk mengetahui distribusi spasial karakteristik tanah tambak di Kabupaten Pangkep Provinsi Sulawesi Selatan. Penentuan titik pengukuran dan pengambilan contoh tanah secara acak sederhana pada 110 titik dan masing-masing pada dua kedalaman tanah yang berbeda yaitu 0-0,2 dan 0,2-0,4 m. Sebanyak 21 karakteristik tanah diukur di lapangan dan dianalisis di laboratorium. Geostatistik dengan metode Kriging dalam Program ArcGIS 9.3 digunakan dalam interpolasi terhadap data tanah yang ada. Distribusi spasial karakteristik tanah ditampilkan dengan memanfaatkan citra ALOS AVNIR- 2 akusisi 21 Juli 2008. Hasil penelitian menunjukkan bahwa secara umum karakteristik tanah tambak di Kabupaten Pangkep tergolong memiliki variabilitas tinggi atau relatif heterogen dengan nilai koefisien variasi yang melebihi $36 \%$ Karakteristik tanah yang menunjukkan kemasaman tanah memiliki pola distribusi spasial yang relatif sama dan demikian juga halnya dengan karakteristik tanah yang menunjukkan kandungan unsur hara tanah juga memiliki pola distribusi spasial yang relatif sama. Derajat kemasaman tanah yang tinggi serta kandungan bahan organik dan $\mathrm{N}$-Total tanah yang tinggi dan sebaliknya kandungan $\mathrm{PO}_{4}$ dan fraksi liat yang rendah secara umum dijumpai di Kecamatan Minasa Te'ne, Pangkajene, Bungoro, Labakkang, dan Ma'rang. Disarankan agar pengelolaan tanah yang dilakukan di tambak Kabupaten Pangkep disesuaikan dengan karakteristik tanahnya yang tergambar secara jelas pada pola distribusi spasial dari masing- masing karakteristik tanah.
\end{abstract}

KATA KUNCl: distribusi spasial, tanah, tambak, Kabupaten Pangkep

ABSTRACT: Spatial Distribution of Brackish Water Ponds Soil Characteristics in Pangkep Regency South Sulawesi Province. By: Rachmansyah and Akhmad Mustafa

Spatial distribution of soil has an important role in the management system of bioenvironment including brackish water pond, as such, the research was conducted to determine the spatial distribution of brackish water pond soil characteristic in Pangkep Regency, South Sulawesi. Simple random sampling technique was employed in the research involving collection of samples in 110 sampling points at a depth of 0-0.2 and 0.2-0.4 m. A total of 21 soil characteristics measured in the field and analyzed in the laboratory. Geostatistic with Kriging method in the ArcGIS 9.3 software was used to interpolate the data. Furthermore, the spatial distribution of the area was presented by making use of ALOS AVNIR-2 image (acquisition July 21, 2008). The result of the research showed that in general, pond soil in Pangkep Regency could be classified as soil with high variability or relatively heterogenic with the value of variation coefficient 
of more than $36 \%$. Not only the characteristics of acidic soil has shown similar pattern of spatial distribution over some areas, but also nutrient rich soil characteristic has the same pattern of distribution. Generally, pond areas in Minasa Te'ne, Pangkajene, Bungoro, Labakkang, and Ma'rang Sub-districts have soil with high value of acidity degree, organic matter and total- $\mathrm{N}$ of soil, and low value of $\mathrm{PO}_{4}$ and clay fraction. It is suggested that pond soil management in the areas has to be based on soil characteristics which has been clearly defined through its pattern spatial distribution.

\section{KEYWORDS: spatial distribution, soil, brackish water pond, Pangkep Regency}

\section{PENDAHULUAN}

Kementerian Kelautan dan Perikanan Republik Indonesia telah memfokuskan untuk menggenjot produksi perikanan budidaya, sehingga peluang sekaligus tumpuan besar akan tertuju pada perikanan budidaya tersebut. Total target produksi perikanan budidaya Indonesia yang ingin dicapai pada tahun 2014 adalah sekitar 16,8 juta ton yang berarti peningkatan produksi sampai 353\% Perikanan budidaya yang sekarang ini dilaksanakan di Indonesia meliputi: budidaya laut, budidaya air payau, dan budidaya air tawar. Potensi lahan perikanan budidaya air payau atau tambak mencapai 1.224.076 ha, akan tetapi yang telah dimanfaatkan seluas 612.530 ha (Mustafa, 2011). Berdasarkan Keputusan Menteri Kelautan dan Perikanan Republik Indonesia Nomor KEP.32/ MEN/ 2010 tentang Penetapan Kawasan Minapolitan, Kabupaten Pangkep (Provinsi Sulawesi Selatan) telah ditetapkan sebagai salah satu wilayah pengembangan Kawasan Minapolitan di Indonesia dengan ikan bandeng (Chanos chanos) dan rumput laut (Gracilaria verrucosa) sebagai komoditas andalan. Tambak di Kabupaten Pangkep mencapai luas kotor 12.527 ha yang digunakan untuk memproduksi udang windu (Penaeus monodon), udang api-api (Metapenaeus monoceros), ikan bandeng (Chanos chanos), ikan mujair (Tilapia mosambica), dan ikan betok (Anabas testudineus) (Anonim, 2009b).

Komoditas yang dibudidayakan di tambak Kabupaten Pangkep tersebut termasuk komoditas yang berbasis lahan. Telah dikenal bahwa lahan merupakan suatu lingkungan fisik yang terdiri atas tanah, topografi, hidrologi, vegetasi, dan iklim. Salah satu faktor lingkungan yang mempengaruhi produktivitas tambak adalah kualitas tanah. Kualitas tanah merupakan faktor produksi utama dalam budidaya tambak sebab dapat mempengaruhi kualitas air, proses biologis, dan rekayasa tambak (Boyd, 1995; Sammut, 1999). Oleh karena itu, kualitas tanah telah umum dipertimbangkan dalam evaluasi kesesuaian lahan untuk budidaya tambak (Boyd, 1995; Salam et al., 2003; Karthik et al., 2005; Mustafa et al., 2007).

Identifikasi dari distribusi spasial karakteristik tanah mempunyai peran penting dalam banyak sistem bio- lingkungan (Zuo et al., 2008; Dong et al., 2009; Akbarzadeh \& TaghizadehMehrjardi, 2010; Zare- Mehrjardi et al., 2010). Pengetahuan mengenai variabilitas spasial karakteristik tanah dan hubungan antar karakteristik tanah sangat diperlukan untuk evaluasi praktek pengelolaan tanah (Huang et al., 2001) dan peningkatan keberlanjutan penggunaan tanah (Liu et al., 2006). Variabilitas adalah salah satu karakteristik hakiki dari kualitas tanah dan dalam ekosistem yang sama kualitas tanah dapat memperlihatkan variasi spasial yang nyata (Robinson \& Metternicht, 2006). Variasi- variasi tersebut adalah terutama muncul dari faktor- faktor dan proses pedogenesis (pembentukan tanah) dan penggunaan lahan (Ersahin, 2003) serta praktek-praktek pengelolaan tanah (PanGozalez et al., 2000; Anuar et al., 2008). Dengan statistik klasik yang mempertimbangkan data tanah sebagai data bebas, maka implementasinya sering menghasilkan hasil yang tidak realistis (Hasany- Pak, 1998 dalam Zare- Mehrjardi et al., 2010). Di samping itu, suatu asumsi yang bertentangan ketika digunakan statistik klasik adalah bahwa karakteristik tanah pada suatu bentang lahan tidak terdistribusi secara acak (variabilitas tidak hanya acak tetapi juga tidak berkorelasi terhadap lokasi spasial) (Essington, 2004). Karakteristik tanah secara alami dapat berbedabeda secara terus- menerus dalam waktu dan tempat, dan untuk kondisi seperti itu sangat sulit jika mungkin mengukur kualitas tanah pada setiap titik di lapangan (Madyaka, 2008). 
Geostatistik dapat digunakan untuk mengkarakteristik dan mengukur variabilitas spasial dari karakteristik tanah, melakukan interpolasi secara rasional dan mengestimasi perbedaan dari nilai yang diinterpolasi (Lin et al., 2001; Essington, 2004). Oleh karena itu, diaplikasikan metode geostatistik untuk lebih mengerti distribusi spasial dari karakteristik tanah tambak di Kabupaten Pangkep Provinsi Sulawesi Selatan agar pengelolaan tanah dapat dilakukan sesuai dengan karakteristik tanahnya.

\section{BAHAN DAN METODE}

\section{Lokasi dan Waktu Penelitian}

Penelitian dilaksanakan di wilayah pesisir Kabupaten Pangkep Provinsi Sulawesi Selatan (Gambar 1) yaitu di Kecamatan Minasa Te'ne, Pangkajene, Bungoro, Labakkang, Ma'rang, Segeri, dan Mandalle pada bulan Maret dan April 2010. Penelitian diawali berupa diskusi dengan staf Dinas Kelautan dan Perikanan Kabupaten Pangkep di Pangkajene untuk mendapatkan informasi umum mengenai lahan budidaya tambak di Kabupaten Pangkep.

\section{Pengumpulan Data}

\section{Data Primer}

Data primer yang dikumpulkan meliputi data kualitas tanah. Penentuan titik pengukuran dan pengambilan contoh tanah ditentukan secara acak sederhana pada 110 titik pengukuran dan pengambilan contoh tanah (Gambar 1) mengikuti petunjuk Hazelton \& Murphy (2009). Peubah kualitas tanah yang diukur langsung di lapangan adalah $\mathrm{pH}_{\mathrm{F}}(\mathrm{pH}$ tanah yang diukur di lapangan) dengan $\mathrm{pH}$ meter (Ahern \& Rayment, 1998), $\mathrm{pH}_{\text {Fox }}(\mathrm{pH}$ tanah yang diukur di lapangan setelah dioksidasi dengan hidrogen peroksida $\left.\left(\mathrm{H}_{2} \mathrm{O}_{2}\right) 30 \%\right)$ dengan pH- meter (Ahern \& Rayment, 1998), dan potensial redoks dengan redox-meter. Contoh tanah diambil pada dua kedalaman tanah yaitu 0-0,2 dan 0,2-0,4 m dari permukaan tanah. Untuk analisis peubah kualitas tanah lainnya, maka contoh tanah yang ada secepatnya dimasukkan dalam kantong plastik dan selanjutnya dimasukkan dalam cool box yang diberi es, karena adanya contoh tanah yang tergolong tanah sulfat masam. Sisa tumbuhan segar, kerikil, cangkang, dan kotoran lainnya dibuang dan bongkahan besar dikecilkan dengan tangan. Contoh tanah di- oven- kan pada suhu $80^{\circ} \mathrm{C}-85^{\circ} \mathrm{C}$ selama $48 \mathrm{jam}$ (Ahern \& Blunden, 1998) untuk tanah sulfat masam, sedangkan contoh tanah lainnya dikeringanginkan. Setelah kering, contoh tanah dihaluskan dengan cara ditumbuk pada lumpang porselin dan diayak dengan ayakan ukuran lubang $2 \mathrm{~mm}$ dan selanjutnya dianalisis di Laboratorium Tanah Balai Penelitian dan Pengembangan Budidaya Air Payau (BPPBAP) di Maros. Kualitas tanah yang dianalisis di laboratorium meliputi $\mathrm{pH}_{\mathrm{KCl}}(\mathrm{pH}$ dari ekstrak $\mathrm{KCl})$ (McElnea \& Ahern, 2004a), $\mathrm{pH}_{\mathrm{ox}}$ (McElnea \& Ahern, 2004b), $S_{p}$ (sulfur peroksida) (Melville, 1993; McElnea \& Ahern, 2004c), $\mathrm{S}_{\mathrm{KCl}}$ (sulfur yang diekstrak dengan $\mathrm{KCl}$ ) (Melville, 1993; McElnea \& Ahern, 2004d), $S_{\mathrm{POS}}\left(\mathrm{S}_{\mathrm{P}}-\mathrm{S}_{\mathrm{KCl}}\right.$ ) (Ahern \& McElnea, 2004), TPA (Titratable Peroxide Acidity atau sebelumnya dikenal dengan Total Potential Acidity) (McElnea \& Ahern, 2004b), TAA (Titratable Actual Acidity atau sebelumnya dikenal dengan Total Actual Acidity) (McElnea \& Ahern, 2004a), TSA (Titratable Sulfidic Acidity atau sebelumnya dikenal dengan Total Sulfidic Acidity) (TPA- TAA) (McElnea \& Ahern, 2004b), pirit (Ahern et al., 1998a; 1998b), karbon organik dengan metode Walkley \& Black (Sulaeman et al., 2005), N-Total dengan metode Kjedhal (Sulaeman et al., 2005), $\mathrm{PO}_{4}$ dengan metode Bray 1 atau Olsen (tergantung $\mathrm{pH}$ tanah) (Sulaeman et al., 2005), Fe dengan spektrofotometer (Menon, 1973), Al dengan spektrofotometer (Menon, 1973), dan tekstur dengan metode hidrometer (Agus et al., 2006).

\section{Data Sekunder}

Data sekunder dikumpulkan melalui penelusuran berbagai laporan, pustaka, dan hasil penelitian dari berbagai instansi terkait. Peta yang dikumpulkan antara lain peta Rupabumi Indonesia skala 1:50.000 dengan nomor lembar 2011- 31 (Lembar Pangkajene), 2011- 33 (Lembar Segeri), dan 2011- 22 (Lembar Balang Lompo) serta peta Administrasi Kabupaten Pangkep.

\section{Analisis Data}

Peta Penutup/ Penggunaan Lahan yang digunakan berasal dari hasil klasifikasi Citra ALOS (Advanced Land Observing Satellite) AVNIR- 2 (The Advanced Visible and Near Infrared Radiometer type 2) akuisisi 21 Juli 2008 dengan Program ER Mapper 7.1 yang diintegrasikan dengan peta dasar dari peta Rupabumi Indonesia. Informasi spasial lain 


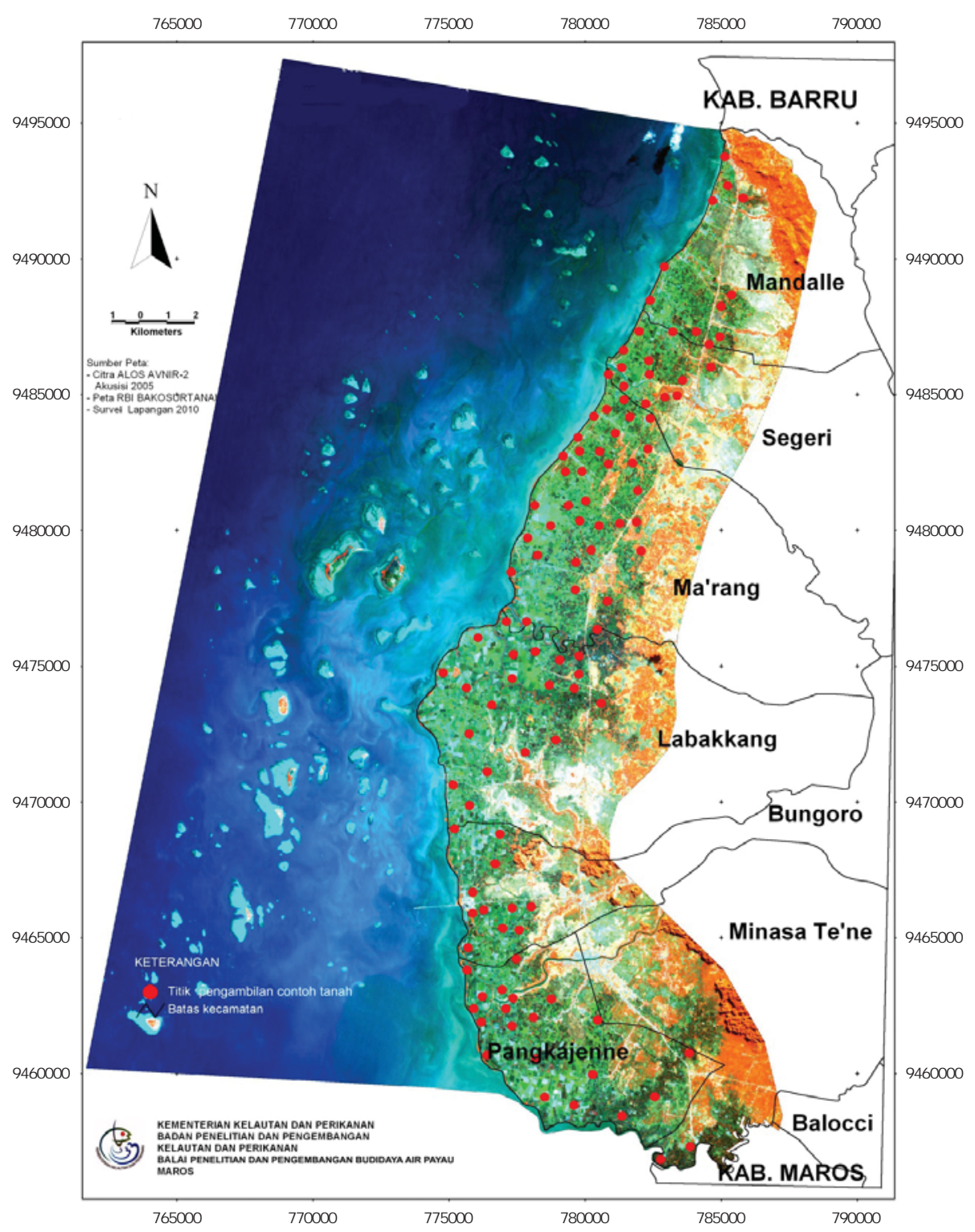

Gambar 1. Titik pengukuran dan pengambilan contoh tanah di kawasan tambak Kabupaten Pangkep Provinsi Sulawesi Selatan

Figure 1. Soil sampling points in the brackish water ponds areas of Pangkep Regency, South Sulawesi Province

yang diperoleh dari data primer dan sekunder juga diintegrasikan dengan peta Penutup/ Penggunaan Lahan. Data dari peubah karakteristik tanah dianalisis dengan metode statistik klasik untuk mendapatkan nilai minimum, maksimum, rata- rata, standar deviasi, koefisien variasi, keruncingan, dan kemencengan berdasarkan petunjuk Sokal \& Rohlf (1981) pada kedalaman tanah yang sama. Metode Kriging (Mulla \& McBratney, 1999; Essington, 2004; Lin, 2008) dalam Program ArcGIS 9.3 digunakan dalam interpolasi terhadap data tanah yang ada pada kedalaman tanah 0- 0,2 m. 


\section{HASIL DAN BAHASAN}

Berdasarkan koefisien keruncingan maka kebanyakan data karaketristik tanah tambak di Kabupaten Pangkep tergolong berdistribusi platikurtik (datar) dengan nilai koefisien keruncingan kurang dari 3 (Tabel 1 dan 2). Dari Tabel
1 dan 2 juga terlihat bahwa data karakteristik tanah di Kabupaten Pangkep lebih banyak distribusinya menceng ke kanan dengan nilai koefisien kemencengan kurang dari 2. Hal ini menunjukkan bahwa data setiap karakteristik tanah tambak di Kabupaten Pangkep memiliki distribusi yang relatif tidak sama.

Tabel 1. Kualitas tanah tambak pada kedalaman 0- 0,2 m di Kabupaten Pangkep Provinsi Sulawesi Selatan $(\mathrm{n}=110)$

Table 1. Soil quality of brackish water pond at the depth of 0-0.2 $\mathrm{m}$ in Pangkep Regency, South Sulawesi Province

\begin{tabular}{|c|c|c|c|c|c|c|c|}
\hline $\begin{array}{l}\text { Peubah } \\
\text { Variables }\end{array}$ & Minimum & $\begin{array}{l}\text { Maksimum } \\
\text { Maximum }\end{array}$ & $\begin{array}{l}\text { Rataan } \\
\text { Average }\end{array}$ & $\begin{array}{l}\text { Standar } \\
\text { deviasi } \\
\text { Standard } \\
\text { deviation }\end{array}$ & $\begin{array}{l}\text { Koefisien variasi } \\
\text { Coefficient of } \\
\text { variance }\end{array}$ & $\begin{array}{l}\text { Kenuncingan } \\
\text { Kurtosis }\end{array}$ & $\begin{array}{c}\text { Kemencengan } \\
\text { Skewness }\end{array}$ \\
\hline $\begin{array}{l}\text { Potensial redoks } \\
\text { Redox potential (m) }\end{array}$ & -395 & 266 & -229.4 & 123.79 & 53.97 & 1.333 & 0.920 \\
\hline $\mathrm{pH}_{\mathrm{F}}$ & 0.95 & 7.80 & 6.82 & 0.758 & 11.11 & 32.330 & -4.477 \\
\hline $\mathrm{pH}_{\mathrm{fox}}$ & 0.21 & 8.05 & 4.12 & 2.535 & 61.49 & -1.536 & -0.070 \\
\hline $\mathrm{pH}_{\mathrm{F}}-\mathrm{pH}_{\mathrm{Fox}}$ & 1.40 & 6.83 & 2.70 & 2.521 & 93.46 & -1.497 & 0.159 \\
\hline $\mathrm{pH}_{\mathrm{kCl}}$ & 2.37 & 8.06 & 6.54 & 1.323 & 20.25 & 1.181 & -1.360 \\
\hline $\mathrm{pH}_{\mathrm{ox}}$ & 0.67 & 8.32 & 4.18 & 2.243 & 53.64 & -1.371 & 0.185 \\
\hline $\mathrm{S}_{\mathrm{Ka}}(\%)$ & 0.00 & 1.63 & 0.37 & 0.399 & 106.56 & 1.202 & 1.469 \\
\hline$S_{p}(\%)$ & 0.02 & 4.12 & 1.37 & 1.195 & 87.53 & -0.850 & 0.703 \\
\hline $\mathrm{S}_{\mathrm{POS}}(\%)$ & 0.02 & 3.47 & 0.99 & 0.892 & 90.00 & -0.303 & 0.822 \\
\hline $\begin{array}{l}\text { TPA (mol H'/ton) } \\
\text { (mole H+/ton) }\end{array}$ & 0.00 & 1500.00 & 218.86 & 355.306 & 162.34 & 3.278 & 1.968 \\
\hline $\begin{array}{l}\text { TAA (mol H'/ton) } \\
\text { (mole } \mathrm{H}+/ \text { ton })\end{array}$ & 0.00 & 66.00 & 3.46 & 11.213 & 324.12 & 14.702 & 3.779 \\
\hline $\begin{array}{l}\text { TSA (mol H'/ton) } \\
\text { (mole } \mathrm{H}+/ \text { ton })\end{array}$ & 0.00 & 1470.00 & 215.41 & 347.916 & 161.52 & 3.320 & 1.966 \\
\hline $\begin{array}{l}\text { Pirit (\%) } \\
\text { Pyrite }\end{array}$ & 0.00 & 6.56 & 0.96 & 1.553 & 161.52 & 3.320 & 1.966 \\
\hline $\begin{array}{l}\text { Bahan organik (\%) } \\
\text { Organic matter }\end{array}$ & 0.00 & 35.43 & 9.38 & 9.755 & 104.02 & 0.542 & 1.248 \\
\hline $\begin{array}{l}\text { N-Total }(\% / \phi \\
\text { Total N }\end{array}$ & 0.00 & 1.189 & 0.353 & 0.2253 & 63.77 & 3.526 & 1.777 \\
\hline $\begin{array}{l}\text { Rasio C:N } \\
\text { C:N ratio }\end{array}$ & 0.00 & 90.946 & 15.754 & 18.6753 & 118.54 & 5.242 & 2.247 \\
\hline $\mathrm{PO}_{4}(\mathrm{mg} / \mathrm{L})$ & 5.478 & 273.692 & 92.500 & 67.2264 & 72.68 & 0.213 & 0.985 \\
\hline $\mathrm{Fe}(\mathrm{mg} / \mathrm{L})$ & 0.00 & 4948.00 & 1624.69 & 1980.652 & 121.91 & -1.363 & 0.661 \\
\hline $\mathrm{A}(\mathrm{mg} / \mathrm{L})$ & 0.00 & 542.500 & 191.788 & 180.4210 & 94.07 & -1.403 & 0.298 \\
\hline $\begin{array}{l}\text { Liat } \\
\text { Clay }(\%)\end{array}$ & 0 & 50 & 14 & 15.1 & 105.84 & -0.515 & 0.831 \\
\hline $\begin{array}{l}\text { Debu } \\
\text { Silt }(\%)\end{array}$ & 14 & 94 & 50 & 18.0 & 36.14 & -0.530 & 0.295 \\
\hline $\begin{array}{l}\text { Pasir } \\
\text { Sand (\%) }\end{array}$ & 0 & 84 & 36 & 19.3 & 53.52 & -0.614 & 0.341 \\
\hline
\end{tabular}


Tabel 2. Kualitas tanah tambak pada kedalaman 0,2-0,4 m di Kabupaten Pangkep Provinsi Sulawesi Selatan $(n=110)$

Table 2. Soil quality of brackish water pond at the depth of 0.2-0.4 $\mathrm{m}$ in Pangkep Regency, South Sulawesi Province

\begin{tabular}{|c|c|c|c|c|c|c|c|}
\hline $\begin{array}{l}\text { Peubah } \\
\text { Variables }\end{array}$ & Minimum & $\begin{array}{l}\text { Maksimum } \\
\text { Maximum }\end{array}$ & $\begin{array}{l}\text { Rataan } \\
\text { Average }\end{array}$ & $\begin{array}{l}\text { Standar } \\
\text { deviasi } \\
\text { Standard } \\
\text { deviation }\end{array}$ & $\begin{array}{l}\text { Koefisien variasi } \\
\text { Coefficient of } \\
\text { variance }\end{array}$ & $\begin{array}{c}\text { Keruncingan } \\
\text { Kirtosis }\end{array}$ & $\begin{array}{l}\text { Kemencengan } \\
\text { Skeuness }\end{array}$ \\
\hline $\begin{array}{l}\text { Potensial redoks } \\
\text { Redox potential (mM) }\end{array}$ & -423 & 86 & -191 & 129.1 & 67.74 & -0.848 & 0.143 \\
\hline $\mathrm{pH}_{\mathrm{F}}$ & 0.95 & 7.81 & 6.62 & 0.864 & 13.06 & 16.960 & -3.328 \\
\hline $\mathrm{pH}_{\text {fox }}$ & 0.00 & 8.27 & 3.85 & 2.526 & 65.64 & -1.599 & 0.001 \\
\hline $\mathrm{pH}_{\mathrm{F}}-\mathrm{pH}_{\mathrm{Fox}}$ & 1.47 & 6.97 & 2.77 & 2.448 & 88.45 & -1.531 & 0.177 \\
\hline $\mathrm{pH}_{\mathrm{ka}}$ & 1.92 & 8.07 & 6.27 & 1.607 & 25.62 & -0.085 & -1.031 \\
\hline $\mathrm{pH}_{\mathrm{ox}}$ & 0.44 & 8.20 & 4.35 & 2.465 & 56.69 & -1.633 & -0.001 \\
\hline $\mathrm{S}_{\mathrm{KC}}(\%)$ & 0.00 & 1.67 & 0.36 & 0.415 & 114.25 & 1.326 & 1.441 \\
\hline$S_{p}(\%)$ & 0.01 & 4.45 & 1.23 & 1.320 & 107.09 & -0.690 & 0.862 \\
\hline $\mathrm{S}_{\mathrm{POS}}(\%$ & 0.14 & 3.42 & 0.87 & 0.982 & 112.99 & -0.330 & 0.938 \\
\hline $\begin{array}{l}\text { TPA (mol H'/ton) } \\
\text { (mole H+/ton) }\end{array}$ & 0.00 & 2141.00 & 262.94 & 447.529 & 170.20 & 3.937 & 2.041 \\
\hline $\begin{array}{l}\text { TAA(mol H'/ton) } \\
\text { (mole H+/ton) }\end{array}$ & 0.00 & 205.00 & 8.92 & 28.560 & 320.21 & 24.143 & 4.580 \\
\hline $\begin{array}{l}\text { TSA (mol H'/ton) } \\
\text { (mole H+/ton) }\end{array}$ & 0.00 & 2139.00 & 254.02 & 429.792 & 169.19 & 4.205 & 2.058 \\
\hline $\begin{array}{l}\text { Pint }(\%) \\
\text { Pyrite }\end{array}$ & 0.00 & 9.55 & 1.13 & 1.919 & 169.19 & 4.205 & 2.058 \\
\hline $\begin{array}{l}\text { Bahan organik }(\%) \\
\text { Organic matter }\end{array}$ & 0.14 & 34.51 & 9.92 & 10.567 & 106.51 & -0.252 & 0.998 \\
\hline $\begin{array}{l}\text { N-Total }(\% / \phi \\
\text { Total N }\end{array}$ & 0.00 & 1.275 & 0.252 & 0.2202 & 87.28 & 4.803 & 2.039 \\
\hline $\begin{array}{l}\text { Rasio C:N } \\
\text { C:N ratio }\end{array}$ & 0.00 & 443.059 & 29.025 & 52.8732 & 182.17 & 34.558 & 5.068 \\
\hline $\mathrm{PO}_{4}(\mathrm{mg} / \mathrm{L})$ & 0.00 & 329.970 & 77.421 & 71.8219 & 92.77 & 0.738 & 1.218 \\
\hline $\mathrm{Fe}(\mathrm{mg} / \mathrm{L})$ & 0.00 & 4845.50 & 1551.12 & 2041.685 & 131.63 & -1.342 & 0.733 \\
\hline $\mathrm{A}(\mathrm{mg} / \mathrm{L})$ & 0.00 & 485.000 & 156.491 & 165.4969 & 105.75 & -1.341 & 0.450 \\
\hline $\begin{array}{l}\text { Liat } \\
\text { Clay }(\% / \%\end{array}$ & 0 & 50 & 17 & 15.8 & 92.98 & -1.115 & 0.577 \\
\hline $\begin{array}{l}\text { Debu } \\
\text { Silt (\%/ }\end{array}$ & 8 & 94 & 46 & 17.0 & 36.70 & -0.122 & 0.405 \\
\hline $\begin{array}{l}\text { Pasir } \\
\text { Sand (\%) }\end{array}$ & 0 & 86 & 37 & 19.5 & 52.89 & -0.569 & 0.509 \\
\hline
\end{tabular}

Nilai koefisien variasi tanah tambak di Kabupaten Pangkep bervariasi dari terendah pada $\mathrm{pH}_{\mathrm{F}}(11,11 \%)$ dan tertinggi pada TAA (324,12\%) untuk kedalaman tanah 0-0,2 m (Tabel 1), sedangkan nilai koefisien variasi terendah juga pada $\mathrm{pH}_{\mathrm{F}}(13,06 \%)$ dan tertinggi juga pada TAA $(320,21 \%$ untuk kedalaman 0,20,4 m (Tabel 2). Telah dilaporkan oleh Goh et al. (1998) bahwa koefisien variasi karakteristik tanah di Sabah (Malaysia) dapat melebihi 100\% pada seri tanah yang sama. Berdasarkan klasifikasi yang ditetapkan oleh Essington 
(2004) maka peubah yang tergolong variabilitas kecil atau relatif homogen yaitu $\mathrm{pH}_{\mathrm{F}}$, peubah yang tergolong variabilitas sedang yaitu $\mathrm{pH}_{\mathrm{KCl}}$, dan peubah kualitas tanah lainnya tergolong variabilitas tinggi atau relatif heterogen baik untuk kedalaman 0-0,2 m maupun kedalaman 0,2-0,4 m. Hal ini menunjukkan bahwa secara umum karakteristik tanah tambak di Kabupaten Pangkep tergolong variabilitas tinggi atau relatif heterogen. Seperti dikatakan oleh Essington (2004) bahwa karakteristik tanah relatif tinggi variabilitasnya terhadap lokasi pada bentang Iahan dan kedalaman tanah. Variabilitas tinggi dari karakteristik tanah dalam seri tanah yang sama juga telah dilaporkan di Semenanjung Malaysia oleh Law \& Tan (1977). Distribusi spasial tanah tambak di Kabupaten Pangkep, secara vertikal dapat dilihat pada Tabel 1 dan 2 dan secara horizontal dapat dilihat pada Gambar 2, 3, 4, dan 5 .

Potensial redoks menggambarkan kondisi tanah yang teroksidasi atau tereduksi. Potensial redoks adalah hasil pengukuran kuantitatif untuk menginformasikan suatu indeks diagnostik dari tingkat anaerobik atau anoksia tanah (Patrick \& Delaune, 1977). Dari Tabel 1 terlihat bahwa potensial redoks tanah pada kedalaman 0-0,2 m lebih rendah daripada kedalaman 0,2- 0,4 m. Dari Gambar 2 terlihat bahwa potensial redoks yang lebih rendah dijumpai tersebar di berbagai kecamatan yang memiliki tambak di Kabupaten Pangkep. Secara umum tanah tambak di Kabupaten Pangkep tergolong dalam kondisi tereduksi yang diperlihatkan dengan nilai potensial redoks tanah yang bernilai negatif. Hal ini sebagai akibat pengambilan contoh tanah dilakukan pada tambak yang sementara dalam proses budidaya, baik budidaya udang windu maupun ikan bandeng secara monokultur maupun polikultur keduanya, sehingga tambak dalam keadaan tergenang air.

$\mathrm{pH}_{\mathrm{F}}$ dapat digunakan untuk indikator secara cepat keberadaan dan kepelikan tanah sulfat masam aktual. Secara umum, $\mathrm{pH}_{\mathrm{F}}$ tanah relatif tinggi pada kedalaman $0-0,2 \mathrm{~m}$ daripada kedalaman tanah 0,2-0,4 m. Hal ini diduga sebagai akibat proses pencucian secara alami dalam jangka waktu yang relatif lama yang membuang senyawa penyebab kemasaman pada permukaan tanah. Selain itu, praktek pengelolaan tanah seperti penggunaan kapur oleh pembudidaya yang menyebabkan tingginya $\mathrm{pH}_{\mathrm{F}}$ tanah di permukaan. Pembudidaya tambak di Kabupaten Pangkep dapat mengaplikasikan kapur pertanian sampai $250 \mathrm{~kg} / \mathrm{ha}$ (Mustafa et al., 2010). Kapur yang diberikan pada permukaan tanah hanya dapat memberikan pengaruh yang nyata sampai kedalaman tanah 0,04 m (de Queiroz et al., 2004) dan 0,05 m (Conyers et al., 2003). Lain halnya dengan pengapuran pematang tambak tanah sulfat masam yang dapat mencapai kedalaman 0,4 m, sebagai akibat adanya rekahan pada pematang sehingga kapur dapat memberikan pengaruh yang nyata sampai kedalaman tersebut (Mustafa, 2007). Pada kedalaman tanah 0-0,2 m terlihat bahwa distribusi spasial $\mathrm{pH}_{\mathrm{F}}$ relatif sama seperti terlihat pada Gambar 2 dan ditunjukkan pula dengan nilai koefisien variasi yang relatif rendah seperti terlihat pada Tabel 1 atau tergolong relatif homogen.

Nilai $\mathrm{pH}_{\mathrm{F}}-\mathrm{pH}_{\mathrm{FOX}}$ sering digunakan sebagai salah satu peubah kualitas tanah untuk mengetahui potensi kemasaman dari tanah. $\mathrm{pH}_{\mathrm{F}}$ adalah $\mathrm{pH}$ tanah yang diukur di lapangan dalam kondisi tanah jenuh dengan air, sedangkan $\mathrm{pH}_{\mathrm{Fox}}$ adalah $\mathrm{pH}$ tanah yang diukur di lapangan setelah dioksidasi sempurna dengan $\mathrm{H}_{2} \mathrm{O}_{2}$ (hidrogen peroksida) 30\%(Ahern $\&$ Rayment, 1998). Terlihat bahwa nilai $\mathrm{pH}_{\mathrm{F}}$ $\mathrm{pH}_{\text {Fox }}$ berkisar antara 1,40 dan 6,83 pada kedalaman 0- 0,2 m dan antara 1,47 dan 6,97 pada kedalaman 0,2-0,4 m. Hal ini menunjukkan bahwa tanah tambak di Kabupaten Pangkep ada yang tergolong tanah sulfat masam. Pada tanah sulfat masam, $\mathrm{pH}_{\mathrm{F}}-\mathrm{pH}_{\mathrm{Fox}}$ dapat melebihi nilai 5 (Mustafa \& Rachmansyah, 2008). Dari Gambar 2 terlihat bahwa ada daerah yang memiliki nilai $\mathrm{pH}_{\mathrm{F}}-\mathrm{pH}_{\mathrm{FOX}}$ yang cukup tinggi di tambak Kabupaten Pangkep yaitu di kecamatan yang berada di bagian selatan seperti: Minasa Te'ne, Pangkajene, Bungoro, Labakkang, dan Ma'rang. Pola distribusi spasial yang relatif sama dengan $\mathrm{pH}_{\mathrm{F}}-\mathrm{pH}_{\mathrm{Fox}}$ adalah pola distribusi spasial dari $\mathrm{pH}_{\mathrm{Ox}}$, tetapi pada daerah yang tinggi nilai $\mathrm{pH}_{\mathrm{F}}-\mathrm{pH}_{\mathrm{FOX}}$ maka sebaliknya rendah $\mathrm{pH}_{\mathrm{ox}} \cdot \mathrm{pH}_{\mathrm{ox}}$ adalah $\mathrm{pH}$ tanah yang telah dikeringkan dan kemudian dioksidasi dengan $\mathrm{H}_{2} \mathrm{O}_{2} 30 \%$ (McElnea \& Ahern, 2004b), sehingga menggambarkan seluruh potensi kemasaman yang ada pada tanah.

Faktor lain yang diduga dapat menjadi penyebab rendahnya potensi kemasaman tanah tambak di bagian utara Kabupaten Pangkep adalah keberadaan karst yang relatif dekat dengan kawasan tambak. Telah dilaporkan bahwa Kawasan Karst Maros- Pangkep 
merupakan yang terbesar dan terindah kedua di dunia setelah kawasan karst di Cina. Gugusan karst yang terdapat di Kabupaten Maros dan Pangkep, Sulawesi Selatan yang sebagian masuk dalam wilayah Taman Nasional Bantimurung Bulusaraung membentang seluas 43.750 ha (Anonim, 2009a). Karst merupakan sumber bahan kapur sehingga diduga dapat menyebabkan penurunan potensi kemasaman tanah.

Pola distribusi spasial kandungan bahan organik juga memiliki pola yang sama dengan
$\mathrm{pH}_{\mathrm{F}}-\mathrm{pH}_{\mathrm{FOx}}$. Hal ini menunjukkan bahwa potensi kemasaman tanah di tambak Kabupaten Pangkep, selain berasal dari pirit juga berasal dari bahan organik. Diduga kandungan bahan organik yang tinggi ini berasal dari lahan mangrove yang dijadikan tambak. Daun yang gugur adalah penyumbang terbesar bahan organik di sedimen hutan mangrove (Koch, 2005). Penguraian bahan organik dapat menghasilkan asam-asam humat yang menyebabkan $\mathrm{pH}$ tanah menjadi lebih rendah. Kemungkinan lain tingginya potensi kemasaman dari tanah vegetasi mangrove
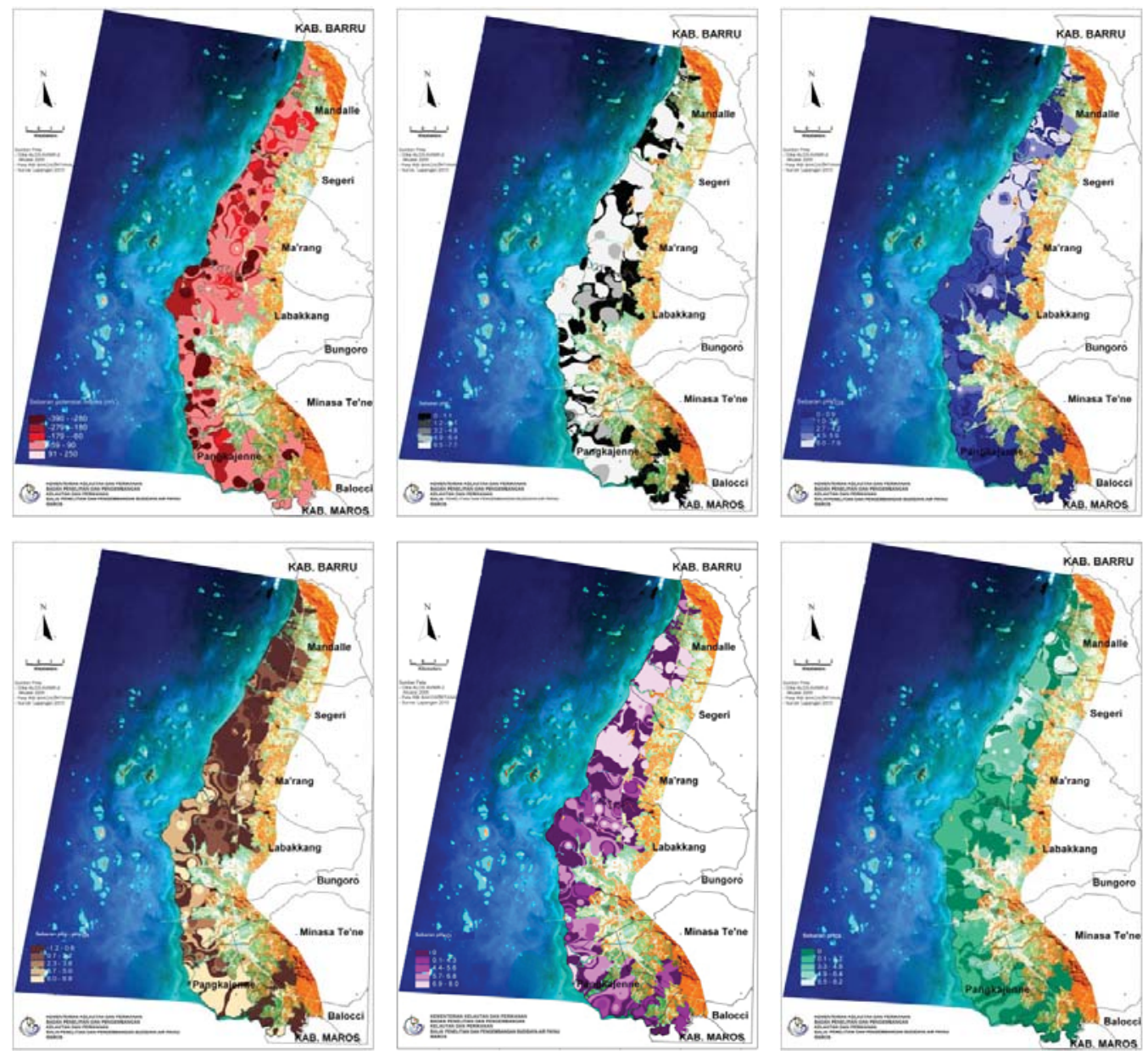

Gambar 2. Peta distribusi spasial potensial redoks (kiri atas), $\mathrm{pH}_{\mathrm{F}}$ (tengah atas), $\mathrm{pH}_{\mathrm{Fox}}$ (kanan atas), $\mathrm{pH}_{\mathrm{F}}-\mathrm{pH}_{\mathrm{FOX}}$ (kiri bawah), $\mathrm{pH}_{\mathrm{KCl}}$ (tengah bawah), dan $\mathrm{pH}_{\mathrm{ox}}$ (kanan bawah) tanah tambak kedalaman 0-0,2 m di Kabupaten Pangkep, Provinsi Sulawesi Selatan

Figure 2. Spatial distribution map of redox potential (top left), $\mathrm{pH}_{\mathrm{F}}$ (top center), $\mathrm{pH}_{\mathrm{FOX}}$ (top right), $\mathrm{pH}_{\mathrm{F}}-\mathrm{pH}_{\mathrm{FOX}}$ (left bottom), $\mathrm{pH}_{K C l}$ (center bottom), and $\mathrm{pH}_{\mathrm{OX}}$ (right bottom) of brackish water pond soil at 0-0.2 m depth in Pangkep Regency, South Sulawesi Province 
sebab adanya kandungan tanin yang tinggi dari Rhizophora sp., Bruguiera sp., Ceriops tagal, Xylocarpus granatum, dan Nypa fruticans yang dapat menyebabkan tanah lebih masam (Sunarto, 2008). Dengan demikian, diduga adanya penutup/penggunaan Iahan tertentu seperti kawasan mangrove dapat menjadi penyebab adanya variasi kandungan bahan organik tanah. Telah dilaporkan sebelumnya oleh Mustafa et al. (2006) bahwa penutup/penggunaan Iahan di kawasan pesisir Kabupaten Pangkep selain kawasan mangrove adalah tambak, sawah, belukar, hutan, ladang, dan pemukiman. Penutup/ penggunaan lahan adalah satu faktor yang menyebabkan adanya variasi karakteristik tanah (Ersahin, 2003).

Hasil pengukuran peubah lain yang menggambarkan kemasaman tanah yaitu $\mathrm{S}_{\mathrm{KCl}}$, $\mathrm{S}_{\mathrm{P}}, \mathrm{S}_{\mathrm{POS}}$, TPA, dan TSA menunjukkan distribusi spasial yang relatif sama dengan peubah kemasaman tanah yang telah dijelaskan sebelumnya yaitu $\mathrm{pH}_{\mathrm{F}}-\mathrm{pH}_{\mathrm{FOX}}$. Dari Gambar 3 terlihat bahwa nilai $\mathrm{S}_{\mathrm{KCl}}, \mathrm{S}_{\mathrm{P}}, \mathrm{S}_{\mathrm{POS}}$. TPA dan TSA tertinggi dijumpai pada tanah tambak yang
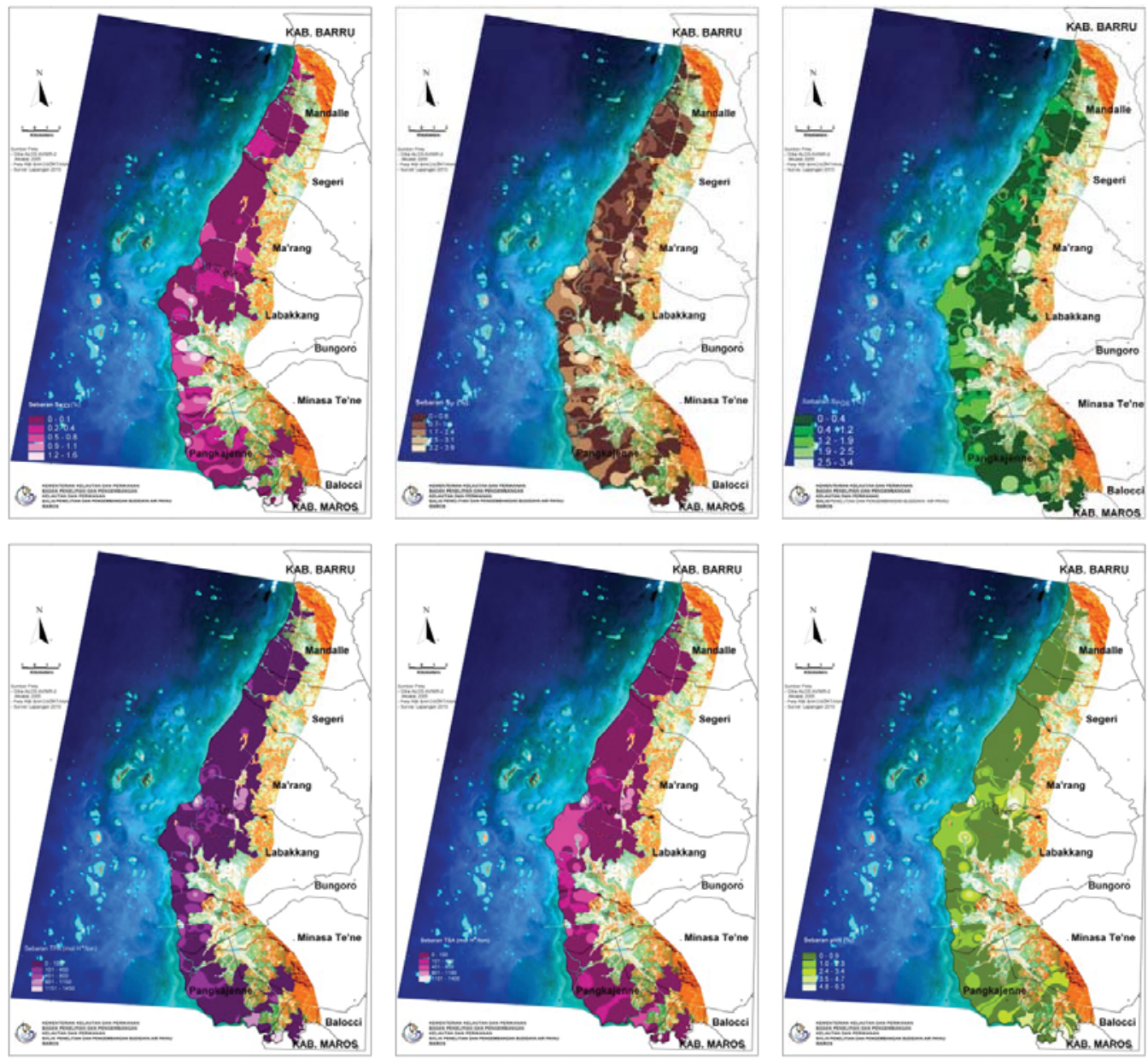

Gambar 3. Peta distribusi spasial $\mathrm{S}_{\mathrm{KCI}}$ (kiri atas), $\mathrm{S}_{\mathrm{p}}$ (tengah atas), $\mathrm{S}_{\mathrm{pOS}}$ (kanan atas), TPA (kiri bawah) dan TSA (tengah bawah), dan pirit (kanan bawah) tanah tambak kedalaman 0- 0,2 m di Kabupaten Pangkep, Provinsi Sulawesi Selatan

Figure 3. Spatial distribution map of $S_{K C I}$ (top left), $S_{P}$ (top center), $S_{P O S}$ (top right), TPA (left bottom), TSA (center bottom), and pyrite (right bottom) of brackish water pond soil at 0-0.2 m depth in Pangkep Regency, South Sulawesi Province 
berlokasi di Kecamatan Minasa Te'ne, Pangkajene, Bungoro, Labakkang, dan Ma'rang. McElnea et al. (2002a; 2002b) menyatakan bahwa pada tanah sulfat masam, terutama yang rendah kandungan bahan organiknya, maka TSA berkorelasi baik dengan $\mathrm{S}_{\text {Pos. }}$. TSA juga mempunyai hubungan secara linier dengan kandungan pirit (Sutrisno, 1990 dalam Noor, 2004) pada tanah sulfat masam. Peubah kualitas tanah yang menggambarkan kemasaman tanah itu secara umum lebih rendah kandungannya pada kedalaman tanah 0-0,2 m daripada kedalaman 0,2-0,4 m. Seperti juga telah dijelaskan sebelumnya adalah sebagai akibat terjadinya pencucian secara alami dalam jangka yang cukup lama yang menyebabkan berkurangnya senyawa atau unsur penyebab kemasaman. Telah dilaporkan oleh Mustafa (2007) bahwa $\mathrm{S}_{\mathrm{POS}}$ tanah dasar tambak menurun dari 2.1300 menjadi 1,8587\%atau berkurang $0,2713 \%$ setelah tanah dasar tambak diremediasi tiga kali selama 72 hari.

Pirit $\left(\mathrm{FeS}_{2}\right)$ merupakan ciri utama dari tanah sulfat masam. Kandungan pirit yang relatif tinggi juga dijumpai di Kecamatan Minasa
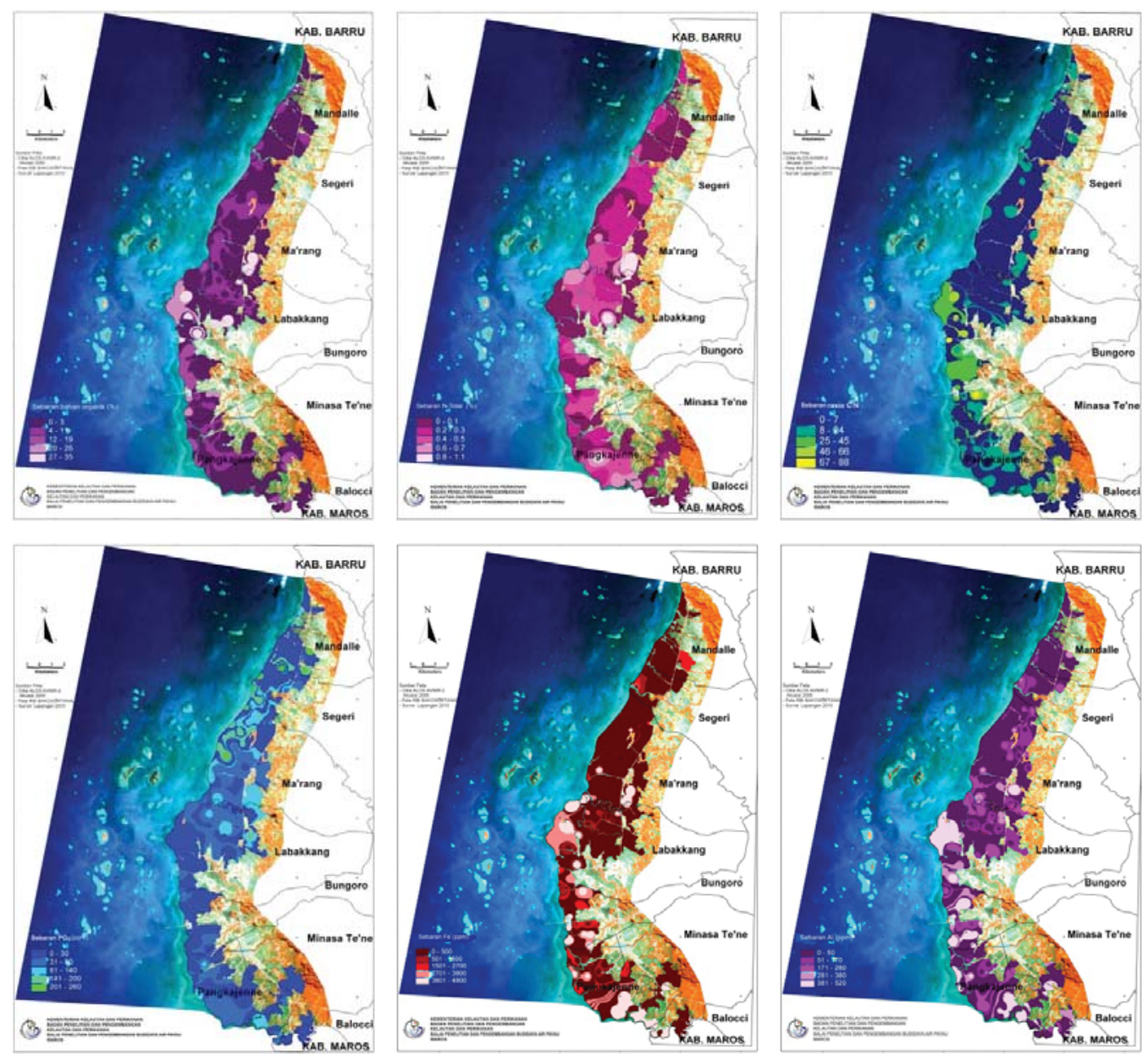

Gambar 4. Peta distribusi spasial bahan organik (kiri atas), N- Total (tengah atas), rasio C:N (kanan atas), $\mathrm{PO}_{4}$ (kiri bawah), Fe (tengah bawah), dan Al (kanan bawah) tanah tambak kedalaman 0- 0,2 m di Kabupaten Pangkep, Provinsi Sulawesi Selatan

Figure 4. Spatial distribution map of organic matter (top left), total $N$ (top center), C: $N$ ratio (top right), $\mathrm{PO}_{4}$ (left bottom), Fe (center bottom), and Al (right bottom) of brackish water pond soil at 0-0.2 m depth in Pangkep Regency, South Sulawesi Province 
Te'ne, Pangkajene, Bungoro, Labakkang, dan Ma'rang (Gambar 3). Faktor-faktor yang mempengaruhi pembentukan pirit adalah jumlah bahan organik, suhu sedimen, pasokan $\mathrm{SO}_{4}$, dan bikarbonat serta suasana anaerob dan kandungan Fe (Dent, 1986). Tingginya kandungan pirit di lima kecamatan pesisir bagian selatan Kabupaten Pangkep tersebut sebagai akibat tingginya kandungan bahan organik (Gambar 4) yang merupakan sumber karbon bagi bakteri dalam pembentukan pirit. Selanjutnya Noor (2004) menyatakan bahwa endapan liat yang berasal dari serat sisa akar vegetasi bakau mengandung pirit yang tinggi. Hal ini didukung oleh pernyataan Ersahin (2003) bahwa variasi- variasi karakteristik tanah selain akibat dari faktor-faktor dan proses penggunaan lahan, juga sebagai akibat faktorfaktor atau proses pedogenesis.

Seperti telah disebutkan sebelumnya, bahwa kandungan bahan organik tanah yang tinggi dijumpai di lima kecamatan pesisir bagian selatan Kabupaten Pangkep. Tanah di lima kecamatan tersebut juga dapat digolongkan sebagai tanah gambut sebab kandungan bahan organiknya lebih tinggi dari 20\% Tanah gambut adalah tanah yang mengandung bahan organik lebih dari $20 \%$ (bila tanah tidak mengandung liat) atau lebih dari 30\% (bila tanah mengandung liat lebih besar dari atau sama dengan 60\%) (Soil Survey Staff, 2001).

Distribusi spasial kandungan unsur hara tanah tambak di Kabupaten Pangkep terlihat pada Gambar 4. Dari Gambar 4 terlihat bahwa kandungan bahan organik, N-Total, Fe, dan Al memiliki pola distribusi yang relatif sama. Bahan organik, selain sebagai sumber karbon, juga merupakan sumber nitrogen (Boyd, 2008). Dengan demikian, tingginya kandungan $\mathrm{N}$-Total tanah pada daerah yang memiliki kandungan bahan organik tanah yang tinggi sebagai akibat dari proses penguraian bahan organik yang menghasilkan nitrogen. Tingginya kandungan Fe dan Al di daerah yang kandungan bahan organiknya tinggi sebagai akibat $\mathrm{pH}$ yang rendah di daerah tersebut yang menyebabkan kelarutan kedua unsur toksik itu menjadi tinggi. Kandungan Al pada tanah sulfat masam meningkat pada $\mathrm{pH}$ yang lebih rendah, yaitu pH 4,0-4,5 (Dent, 1986). Selain itu, kandungan Al pada tanah sulfat masam berkaitan dengan oksidasi pirit. Suasana yang sangat masam mempercepat pelapukan mineral alumino- silikat akibat perusakan kisi dari mineral tipe 2:2 (seperti montmorillonit) menjadi mineral tipe 1:1 (kaolinit) dengan membebaskan dan melarutkan Al yang lebih banyak (Pons, 1973). Kandungan Fe dan Al yang tinggi di Kecamatan Minasa Te'ne, Pangkajene, Bungoro, Labakkang, dan Ma'rang menyebabkan kandungan $\mathrm{PO}_{4}$ (fosfat) tanah relatif lebih rendah. Hal ini sebagai akibat dari Fe dan Al tanah yang dapat menyebabkan $\mathrm{PO}_{4}$ menjadi tidak tersedia. Pada tanah yang pHnya rendah, $\mathrm{PO}_{4}$ diikat secara kuat oleh Fe dan $\mathrm{Al}$ dalam bentuk $\mathrm{FePO}_{4}$ atau $\mathrm{AlPO}_{4}$ yang tidak larut (Kselik et al., 1992; Tu et al., 1993; Mustafa \& Sammut, 2007). Dari Gambar 4 terlihat bahwa kandungan $\mathrm{PO}_{4}$ yang rendah dijumpai pada daerah yang kandungan Fe dan Al-nya tinggi.

Tekstur tanah merupakan perbandingan antara fraksi liat, debu, dan pasir dari tanah. Tekstur tanah tambak sangat berpengaruh terhadap porositas dan pertumbuhan klekap yang dapat menjadi salah satu sumber makanan bagi ikan dan udang. Tanah tambak sering dijumpai bertekstur halus dengan kandungan liat minimal 20\% 30\%untuk menahan peresapan ke samping (Boyd, 1995). Dikatakan pula bahwa suatu material tanah yang merupakan campuran dari partikel yang berbeda ukuran dan mengandung minimum 30\%liat adalah ideal untuk konstruksi tambak. Secara umum, kandungan fraksi liat tanah tambak yang tinggi dijumpai di kecamatan pesisir bagian utara Kabupaten Pangkep, sebaliknya kandungan fraksi pasir yang tinggi dijumpai di kecamatan pesisir bagian selatan Kabupaten Pangkep (Gambar 5). Oleh karena itu, kandungan fraksi liat, debu, dan pasir tanah tambak di Kabupaten Pangkep relatif heterogen yang ditandai dengan nilai koefisien variasi yang relatif besar baik pada kedalaman 0- 0,2 m (Tabel 1 ) maupun pada kedalaman tanah 0,2-0,4 m (Tabel 2).

\section{KESIMPULAN DAN SARAN}

Tanah tambak di Kabupaten Pangkep tergolong tanah Aluvial non-sulfat masam, tanah sulfat masam, dan tanah gambut. Secara umum, karakteristik tanah tambak tergolong memiliki variabilitas tinggi atau relatif heterogen dengan nilai koefisien variasi yang melebihi 36\% Karakteristik tanah yang menunjukkan kemasaman tanah memiliki pola distribusi spasial yang relatif sama dan demikian juga halnya dengan karakteristik tanah yang menunjukkan kandungan unsur hara tanah juga memiliki pola distribusi spasial 

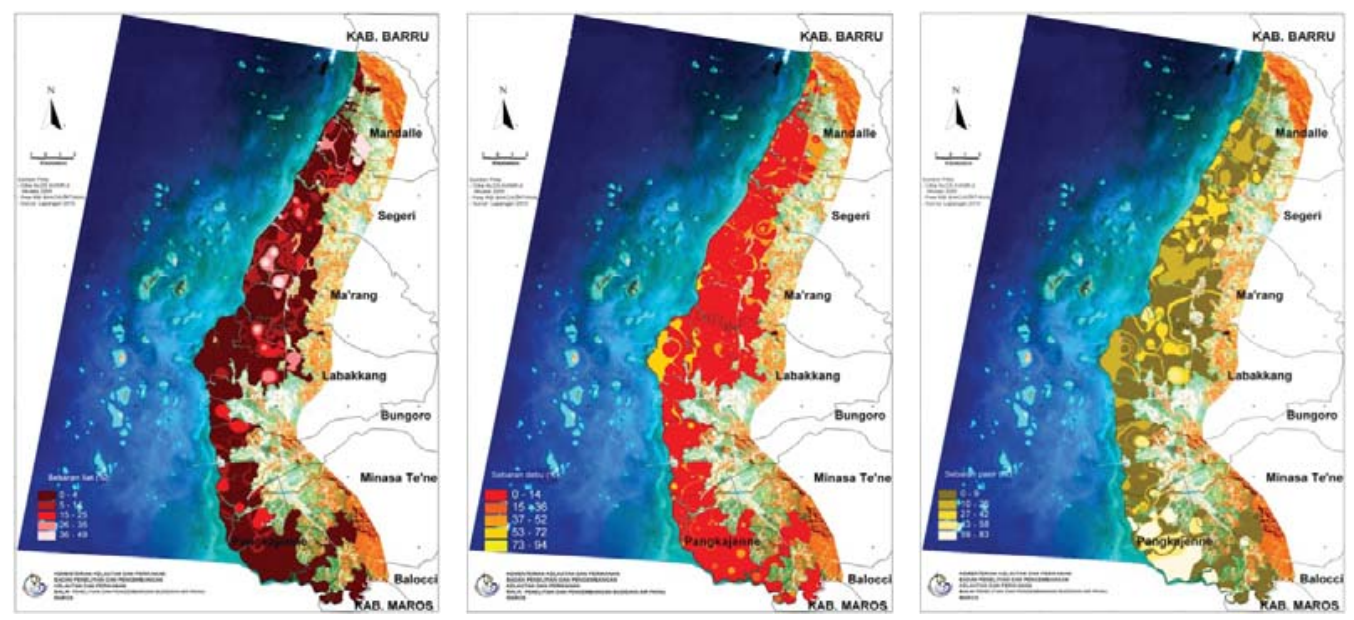

Gambar 5. Peta distribusi spasial kandungan fraksi liat (kiri), debu (tengah), dan pasir (kanan) tanah tambak kedalaman 0- 0,2 m di Kabupaten Pangkep, Provinsi Sulawesi Selatan

Figure 5. Spatial distribution map of clay fractions (left), silt (center), and sand (right) of brackish water pond soil depth at 0-0.2 m in Pangkep Regency, South Sulawesi Province

yang relatif sama. Derajat kemasaman tanah yang tinggi serta kandungan bahan organik dan $\mathrm{N}$ - Total tanah yang tinggi dan sebaliknya kandungan $\mathrm{PO}_{4}$ dan fraksi liat yang rendah secara umum dijumpai di Kecamatan Minasa Te'ne, Pangkajene, Bungoro, Labakkang, dan Ma'rang. Disarankan agar pengelolaan tanah yang dilakukan di tambak Kabupaten Pangkep disesuaikan dengan karakteristik tanahnya yang tergambar pada pola distribusi spasial dari masing- masing karakteristik tanah.

\section{UCAPAN TERIMA KASIH}

Diucapkan terima kasih kepada Darsono dan Haking Made atas bantuannya dalam pengukuran dan pengambilan contoh tanah dan juga Kamariah, Rahmiyah, dan Rismawati atas bantuan dalam analisis kualitas tanah di laboratorium.

\section{DAFTARACUAN}

Agus, Yusrial, F., \& Sutono. 2006. Penetapan tekstur tanah. Dalam: Kurnia, U., Agus, F., Adimihardja, A., \&Dariah, A. (Eds.) Sifat Fisik Tanah dan Metode Analisisnya. Balai Besar Penelitian dan Pengembangan Sumberdaya Lahan Pertanian, Bogor, hlm. 43- 62.

Ahern, C.R. \& Blunden. B. 1998. Designing a soil sampling and analysis program. In: Ahern, C.R., Blunden, B., \& Stone, Y. (Eds.) Acid Sulfate Soils Laboratory Methods
Guidelines. Acid Sulfate Soil Management Advisory Committee, Wollongbar, NSW, p. 2.1-2.6.

Ahern, C.R. \& McElnea, A.E. 2004. Calculated sulfur parameters. In: Acid Sulfate Soils Laboratory Methods Guidelines. Queensland Department of Natural Resources, Mines and Energy, Indooroopilly, Queensland, Australia, p. B11-1- B11- 2.

Ahern, C.R., McElnea, A., \& Baker, D.E. 1998a. Peroxide oxidation combined acidity and sulfate. In: Ahern, C.R., Blunden, B., \& Stone, Y. (Eds.) Acid Sulfate Soils Laboratory Methods Guidelines. Acid Sulfate Soil Management Advisory Committee, Wollongbar, NSW, p. 4.1-4.17.

Ahern, C.R., McElnea, A., \& Baker, D.E. 1998b. Total oxidisable sulfur. In: Ahern, C.R., Blunden, B., \&Stone, Y. (Eds.) Acid Sulfate Soils Laboratory Methods Guidelines. Acid Sulfate Soil Management Advisory Committee, Wollongbar, NSW, p. 5.1- 5.7.

Ahern, C.R. \& Rayment, G.E. 1998. Codes for acid sulfate soils analytical methods. In: Ahern, C.R., Blunden, B., \& Stone, Y. (Eds.) Acid Sulfate Soils Laboratory Methods Guidelines. Acid Sulfate Soil Management Advisory Committee, Wollongbar, NSW, p. 3.1-3.5.

Akbarzadeh, A. \& Taghizadeh-Mehrjardi, R. 2010. Spatial distribution of some soil 
properties, using geostatistical methods in Khezrabad Region (Yazd) ofIran. ProEnvironment, 3: 100-109.

Anonim. 2009a. Karst Maros Pangkep terluas kedua di dunia. http://alamendah. wordpress.com/ 2009/ 10/ 06/ karst- marospangkep- terluas- kedua- di- dunia/ . Diakses tanggal 06 Mei 2011.

Anonim. 2009b. Laporan Statistik Perikanan Sulawesi Selatan, 2008. Dinas Perikanan dan Kelautan Provinsi Sulawesi Selatan, Makassar, $243 \mathrm{hlm}$.

Anuar, A.R., Goh, K.J., Heoh, T.B., \&Ahmed, O.H. 2008. Spatial variability of soil inorganic $N$ in a mature oil palm plantation in Sabah, Malaysia. American J. of Applied Sciences, 5(9): 1,239- 1,246.

Boyd, C.E. 1995. Bottom Soils, Sediment, and Pond Aquaculture. Chapman and Hall, New York, $348 \mathrm{pp}$.

Boyd, C.E. 2008. Pond bottom soil analyses. Global Aquaculture Advocate September/ October, p. 91- 92.

Conyers, M.K., Heenan, D.P., McGhie, W.J., \& Poile, G.P. 2003. Amelioration of acidity with time by limestone under contrasting tillage. Soil \& Tillage Research, 72: 85- 94.

Dent, D. 1986. Acid Sulphate Soils: A Baseline for Research and Development. ILRI Publication 39. International Institute for Land Reclamation and Improvement, Wageningen, $204 \mathrm{pp}$.

Dong, X.W., Zhang, X.K., Bao, X.L., \& Wang, J.K. 2009. Spatial distribution of soil nutrients after the establishment of sand-fixing shrubs on sand dune. Plant Soil Environment, 55(7): 288-294.

Ersahin, S. 2003. Comparing ordinary kriging and cokriging to estimate infiltration rate. Soil Science, 67: 1,848- 1,855.

Essington, M.E. 2004. Soil and Water Chemistry: An Integrative Approach. CRC Press, Boca Raton, 534 pp.

Goh, K.J., Kee, K.K., \& Chew, P.S. 1998. Soil fertility status of some common soils in Sabah, Malaysia. In: Aziz, B. \& Husni, A.M.S. (Eds.) Proceedings of the Soil Science Conference of Malaysia. Malaysian Society of Soil Society, Kuala Lumpur, p. 1- 16.

Hazelton, P. \& Murphy, B. 2009. Interpreting Soil Test Results: What do All the Numbers Mean? CSIRO Publishing, Collingwood, 152 $\mathrm{pp}$.
Huang, X., Skidmore, E.L., \& Tibke, G. 2001. Spatial variability of soil properties along a transect of CRP and continuously cropped Iand. In: Stott, D.E., Mohtar, R.E., \& Steinhardt, G.C. (Eds.) Sustaining the Global Farm. Selected papers from $10^{\text {th }}$ International Soil Conservation Organization Meeting held May 24- 29, 1999 at Purdue University and the USDA- ARS National Soil Erosion Research Laboratory, p. 641- 647.

Karthik, M., Suri, J., Saharan, N., \& Biradar, R.S. 2005. Brackish water aquaculture site selection in Palghar Taluk, Thane district of Maharashtra, India, using the techniques of remote sensing and geographical information system. Aquacultural Engineering, 32: 285- 302.

Koch, B.P. 2005. Organic Matter Pathways in a Mangrove System in Northen Brazil Chemical Tracers of Major Sources under the Influence of Sedimentation and Biological Degradation. Center for Tropical Marine Ecology, Bremen, 109 pp.

Kselik, R.A.L., Smilde, K.W., Ritzema, H.P., Subagyono, K., Saragih, S., Damanik, M., \& Suwardjo, H. 1992. Integrated research on water management, soil fertility and cropping systems on acid sulphate soils in South Kalimantan, Indonesia. In: Dent, D.L. $\&$ van Mensvoort, M.E.F. (Eds.) Selected Papers of the Ho Chi Minh City Symposium on Acid Sulphate Soils. ILRI Publication 53. International Institute for Land Reclamation and Improvement, Wageningen, p. 177194.

Law, W.M. \& Tan, M.M. 1977. Chemical properties of some Peninsular Malaysian soil series. In: Proceedings of Chemistry and Fertility of Tropical Soils. Malaysian Society of Soil Society, Kuala Lumpur, p. 180- 191.

Lin, Y.P. 2008. Simulating spatial distributions, variability and uncertainty of soil arsenic by geostatistical simulations in geographic information systems. Open Environmental Sciences, 2: 26- 33.

Lin, Y.P., Chang, T.K., \&Teng, T.P. 2001. Characterization of soil lead by comparing sequential Gaussian simulation, simulated annealing simulation and kriging methods. Environmental Geology, 41: 189- 199.

Liu, D., Wang, Z., Zhang, B., Song, K., Li, X., Li, J., Li, F., \&Duan, H. 2006. Spatial distribution of soil organic carbon and analysis of related factors in croplands of the black soil 
region, Northeast China. Agriculture, Ecosystems and Environment, 113: 73-81.

Madyaka, M. 2008. Spatial Modelling and Prediction of Soil Salinization Using SaltMod in a GIS Environment. Master of Science Thesis. International Institute for Geo- Information Science and Earth Observation, Enschede, The Netherlands, $128 \mathrm{pp}$.

McElnea, A.E. \&Ahern, C.R. 2004a. KCl extractable $\mathrm{pH}\left(\mathrm{pH}_{\mathrm{KCl}}\right)$ and titratable actual acidity (TAA). In: Acid Sulfate Soils Laboratory Methods Guidelines. Queensland Department of Natural Resources, Mines and Energy, Indooroopilly, Queensland, Australia, p. B21-B2-3.

McElnea, A.E. \& Ahern, C.R. 2004b. Peroxide $\mathrm{pH}\left(\mathrm{pH}_{\mathrm{ox}}\right)$, titratable peroxide acidity (TPA) and excess acid neutralising capacity $\left(\mathrm{ANC}_{\mathrm{E}}\right.$ ). In: Acid Sulfate Soils Laboratory Methods Guidelines. Queensland Department of Natural Resources, Mines and Energy, Indooroopilly, Queensland, Australia, p. B3-1-B3- 7.

McElnea, A.E. \& Ahern, C.R. 2004c. Sulfur-peroxide oxidation method. In: Acid Sulfate Soils Laboratory Methods Guidelines. Queensland Department of Natural Resources, Mines and Energy, Indooroopilly, Queensland, Australia, p. B7- 1- B7- 2.

McElnea, A.E. \& Ahern, C.R. 2004d. Sulfur 1M $\mathrm{KCl}$ extraction $\left(\mathrm{S}_{\mathrm{KCl}}\right)$. In: Acid Sulfate Soils Laboratory Methods Guidelines. Queensland Department of Natural Resources, Mines and Energy, Indooroopilly, Queensland, Australia, p. B8- 1- B8- 2.

McElnea, A.E., Ahern, C.R., \& Menzies, N.W. 2002a. Improvements to peroxide oxidation methods for analysing sulfur in acid sulfate soils. Australian J. of Soil Research, 40: 1,115-1,132.

McElnea, A.E., Ahern, C.R., \& Menzies, N.W. $2002 \mathrm{~b}$. The measurement of actual acidity in acid sulfate soils and the determination of sulfidic acidity in suspension after peroxide oxidation. Australian J. of Soil Research, 40: 1,133- 1,157.

Melville, M.D. 1993. Soil Laboratory Manual. School of Geography, The University of New South Wales, Sydney, 74 pp.

Menon, R.G. 1973. Soil and Water Analysis: A Laboratory Manual for the Analysis of Soil and Water. Proyek Survey O.K.T. Sumatera Selatan, Palembang, 190 pp.
Mulla, D.J. \& McBratney, A.B. 1999. Soil spatial variability. In: Sumner, M.E. (Ed.), Handbook of Soil Science. CRC Press, Boca Raton, p. A321-A352.

Mustafa, A. 2007. Improving Acid Sulfate Soils for Brackish Water Ponds in South Sulawesi, Indonesia. Ph.D. Thesis. The University of New South Wales, Sydney, 418 pp.

Mustafa, A. 2007. Teknologi Pendayagunaan Tanah Sulfat Masam untuk Akuakultur Berkelanjutan. Orasi Pengukuhan Profesor Riset Bidang Akuakultur, Jakarta, 28 November 2011. Badan Penelitian dan Pengembangan Kelautan dan Perikanan, Jakarta, $97 \mathrm{hlm}$.

Mustafa, A. \& Rachmansyah. 2008. Kebijakan dalam pemanfaatan tanah sulfat masam untuk budidaya tambak. Dalam: Sudradjat, A., Rusastra, I W., \& Budiharsono, S. (Eds.) Analisis Kebijakan Pembangunan Perikanan Budidaya. Pusat Riset Perikanan Budidaya, Jakarta. hlm. 1- 11.

Mustafa, A., Rachmansyah, \& Hanafi, A. 2007. Kelayakan Lahan untuk Budi Daya Perikanan Pesisir. Dalam: Kumpulan Makalah Bidang Riset Perikanan Budidaya. Disampaikan pada Simposium Kelautan dan Perikanan pada tanggal 7 Agustus 2007 di Gedung Bidakara, Jakarta. Pusat Riset Perikanan Budidaya, Jakarta, $28 \mathrm{hlm}$.

Mustafa, A., Ratnawati, E., \& Utojo. 2010. Penentuan faktor pengelolaan tambak yang mempengaruhi produktivitas tambak di Kabupaten Pangkep Provinsi Sulawesi Selatan. Dalam: Syamsuddin, S., Sipahutar, Y.H., Saifurridjal, Basith, A., Nurbani, S.Z., Suharto, Siregar, A.N., Rahardjo, S., Hadi, R.S., \& Sanova, V. (Eds.), Prosiding Seminar Nasional Perikanan 2010: Budidaya Perikanan. Pusat Penelitian dan Pengembangan Masyarakat, Sekolah Tinggi Perikanan, Jakarta, hlm. 320- 329.

Mustafa, A. \& Sammut, J. 2007. Effect of different remediation techniques and dosages of phosphorus fertilizer on soil quality and klekap production in acid sulfate soilaffected aquaculture ponds. Indonesian Aquaculture Journal, 2(2): 141- 157.

Mustafa, A., Utojo, Hasnawi, \& Rachmansyah. 2006. Validasi data Iuas lahan budi daya tambak di Kabupaten Maros dan Pangkep, Provinsi Sulawesi Selatan dengan menggunakan teknologi penginderaan 
jauh dan sistem informasi geografis. J. Ris. Akuakultur, 1(3): 419- 430.

Noor, M. 2004. Lahan Rawa: Sifat dan Pengelolaan Tanah Bermasalah Sulfat Masam. PT RajaGrafindo Persada, Jakarta, $238 \mathrm{hlm}$.

PanGonzalez, A., Vieira, S.R., \&Taboada, C.M.T. 2000. The effect of cultivation on the spatial variability of selected properties of an umbric horizon. Geoderma, 97(3- 4): 273292.

Patrick, W.H.Jr. \& Delaune, R.D. 1977. Chemical and biological redox systems affecting nutrient availability in the coastal wetlands. Geoscience and Man, 18: 131- 137.

Pons, L.J. 1973. Outline of genesis, characteristics, classification and improvement of acid sulphate soil. In: Dost, H. (Ed.) Acid Sulphate Soils. ILRI Publication 18. International Institute for Land Reclamation and Improvement, Wageningen, p. 1- 27.

Robinson, T.P. \& Metternicht, G. 2006. Testing the performance of spatial interpolation techniques for mapping soil properties. Computer and Electronics in Agriculture, 50: 97- 108.

de Queiroz, J.F., Nicolella, G., Wood, C.W., \& Boyd, C.E. 2004. Lime application methods, water and bottom soil acidity in fresh water fish ponds. Piracicaba Sept./Oct. Scientia Agricola, 61(5).

Salam, M.A., Ross, L.G., \& Beveridge, C.M.M. 2003. A comparison of development opportunities for crab and shrimp aquaculture in southwestern Bangladesh, using GIS modeling. Aquaculture, 220: 477- 494.

Sammut, J. 1999. Amelioration and management of shrimp ponds in acid sulfate soils: key researchable issues. In: Smith, P.T. (Ed.), Towards Sustainable Shrimp Culture in Thai- land and the Region. ACIAR Proceedings No. 90. Australian Centre for International Agricultural Research, Canberra, p. 102106.

Soil Survey Staff. 2001. Soil Taxonomy, a Basic System of Soil Classification for Making and Interpreting Soil Survey. United State Department of Agriculture, Washington, D.C., $734 \mathrm{pp}$.

Sokal, R.R. \& Rohlf, F.J. 1981. Biometry: The Principles and Practice of Statistics in Biological Research. Second edition: W.H. Freeman and Co., New York, 859 pp.

Sulaeman, Suparto, \& Eviati. 2005. Petunjuk Teknis Analisis Kimia Tanah, Tanaman, Air, dan Pupuk. Diedit oleh: Prasetyo, B.H., Santoso, D., \& Widowati, L. R. Balai Penelitian Tanah, Bogor, $136 \mathrm{hlm}$.

Sunarto. 2008. Peranan Ekologis dan Antropogenesis Ekosistem Mangrove. Karya Ilmiah. Fakultas Perikanan dan IImu Kelautan, Universitas Padjadjaran, Jatinangor, $34 \mathrm{hlm}$.

Tu, S.X., Guo, Z.F., \& Chen, S.S. 1993. Transformation of applied phosphorus in a calcareous fluvisol. Pedosphere, 3: 277- 283.

Zare- Mehrjardi, M., Taghizadeh- Mehrjardi, R., $\&$ Akbarzadeh, A. 2010. Evaluation of geostatistical techniques for mapping spatial distribution of soil pH, salinity and plant cover affected by environmental factors in Southern Iran. Notulae Scientia Biologicae, 2(4): 92- 103.

Zuo, X.A., Zhao, H.L., Zhao, X.Y., Zhang, T.H., Guo, Y.R., Wang, S.K., \& Sam, D. 2008. Spatial pattern and heterogeneity of soil properties in sand dunes under grazing and restoration in Horqin Sandy Land, Northern China. Soil and Tillage Research, 99: 202- 212. 